\title{
Design of Automatic Discharge Drive for Drill Pipe of Marine Drilling Rig
}

\author{
Guodong Tian \\ CNOOC Energy Development Equipment Technology Co, Ltd. Tianjin Tanggu, 300452, China
}

Keywords: Ocean, Drill Pipe, Automatic Discharge, Driving Device

\begin{abstract}
The important role of drill pipe of offshore drilling rig in offshore oil exploitation forms a positive driving force for the development of national economy. With the increase of the scale and difficulty of offshore drilling operation, it has become an inevitable trend of marine drilling development to give full play to the advantages of the automatic discharge system of drill pipe of offshore drilling rig. This paper studies the design of automatic discharge drive device for drill pipe of marine drilling rig, aiming to provide positive ideas for modern marine drilling operation.
\end{abstract}

\section{Application Type of Drill Pipe for Ocean Drilling Rig}

The offshore drilling operation is an important way to develop and utilize the marine field in China. Because of the high labor intensity and dangerous degree of offshore drilling operation, the automatic discharge of drill pipe by offshore drilling rig can greatly improve the working efficiency and reduce the labor cost. In the design of the automatic discharge drive device of the drill pipe of the marine drilling rig, the automatic discharge mode of the drill pipe of the marine drilling rig can be effectively designed, the discharge drive can be controlled scientifically and reasonably, and the mechanized control of the offshore drilling operation can be completed by using the effective driving device to improve the working performance level of the marine drilling rig in China.

\subsection{Star-Type Marine Drill Pipe}

Star marine drill pipe is the most basic type of drill pipe for marine drill. The drill pipe of the star-shaped offshore drilling rig can be rotated around the central shaft and the driving force of the hydraulic system can be used as the driving power supply mode to make the drill pipe of the offshore drilling rig achieve the purpose of automatic discharge, and the drill pipe of the offshore drilling rig can automatically move to the wellhead position of the offshore drilling rig[1]. The drill pipe of star-type marine drilling rig has the characteristics of flexibility and less discharge rod, which is generally suitable for smaller equipment in marine drilling.

\subsection{Parallel Marine Drilling Rig Drill Pipe}

The biggest difference between the drill pipe of parallel offshore drilling rig and the drill pipe of star offshore drilling rig is that the drill pipe of parallel offshore drilling rig needs to realize the running track of installing drill pipe of offshore drilling rig. The drill pipe of parallel marine drilling rig will move along the preset parallel track to the drilling wellhead position. Each finger beam of the drill pipe of parallel marine drilling rig can be operated independently without affecting each other, thus improving the working effect of the drill pipe of marine drilling rig. Multiple drill pipe devices can be designed in the structure of parallel marine drill pipe, which can be applied to large drilling conditions.

\subsection{Xy Drill Pipe for Marine Drilling Rig}

Drill pipe of XY type marine drilling rig has similarities with drill pipe structure of parallel type marine drilling rig. XY type of drill pipe of marine drilling rig is arranged on both sides of the well head of marine drilling, and the finger beams of the drill pipe designed for marine drilling rig are arranged. A finger beam of XY drill pipe located on both sides of the track can be operated along the same track, which greatly improves the working efficiency of the drill pipe of the offshore drilling rig[2]XY drilling rigs need to be fixed above the Derrick of the offshore drilling rigs to 
operate, which limits the number of discharge drill pipes in the drill pipe construction of the XY offshore drilling rigs. The drill pipes of the offshore drilling rigs are not suitable for large drilling operations.

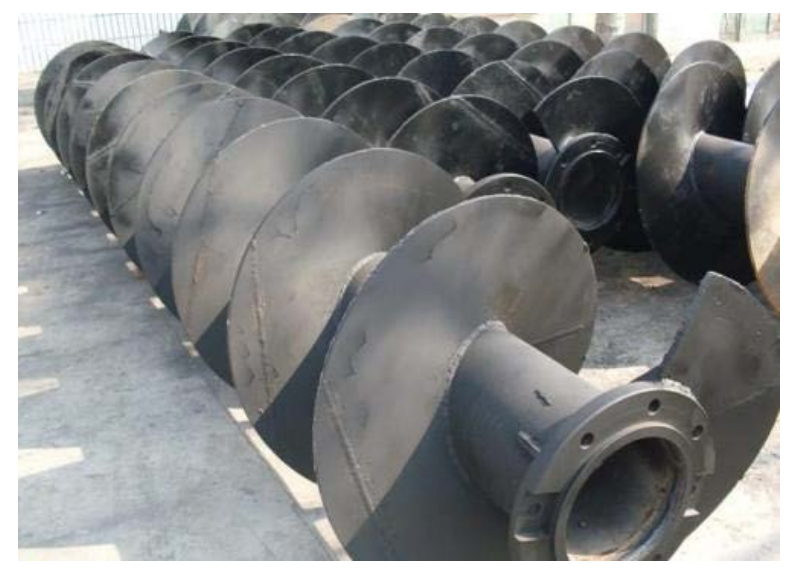

Figure 1 Drilling rigs for marine drilling rigs

\section{Application of Ocean Drilling Rig Drill}

\subsection{Safety of Drill Pipe Application in Marine Drilling Rig}

The drill pipe of marine drilling rig is an important equipment in marine drilling work and plays an irreplaceable role in the process of marine drilling. In the whole process of ocean drilling, it is necessary to carry out drill pipe, casing and other processes continuously. These processes not only greatly consume the time of ocean drilling, but also bring great safety risks to marine drilling personnel. By using the drill pipe of marine drilling rig, the manual operation process can be greatly reduced, and the mechanization degree of marine drilling can be improved, thus improving the safety of the whole marine drilling work.

\subsection{Economy of Drill Pipe Application in Marine Drilling Rig}

The application of drill pipe in marine drilling rig also has great economic advantages. Marine drilling work is a long time-consuming and heavy workload construction process, the traditional offshore drilling work needs to use a large number of drilling personnel to participate in it, which makes the labor cost expenditure of offshore drilling account for a large proportion of the total cost, such as the wage expenditure in the labor cost and so on. Using the drill pipe of marine drilling rig to carry on the drilling work can greatly save the labor cost and then improve the economic benefit. In addition, the use of drill pipe of offshore drilling rig can significantly save the time limit of offshore drilling[3]. Marine drilling is generally deep-sea operations. With the increase of the depth of offshore drilling, artificial drilling methods must take full account of such problems as the bearing capacity of personnel, especially the increase in the number of offshore drilling columns will also consume more time. When the drill pipe automatic discharge mode is adopted, the automatic discharge system can avoid the limitation of manual way, improve the working efficiency by speeding up the speed of the offshore drilling column, and reduce the time spent in the whole drilling process. The automatic discharge of drill pipe of marine drilling rig can also significantly improve the stability of the work, reduce the energy consumption of drilling in a stable working condition, and then reduce the unnecessary cost.

\subsection{Standard Character of Drill Pipe Application in Marine Drilling Rig}

With the popularization of the application of automatic discharge of drill pipe in marine drilling rig, more explicit regulations have been made on the work of offshore drilling. The standard of drill pipe application of marine drilling rig is also gradually improved. The operation flow of marine drilling for automatic discharge of drill pipe of marine drilling rig has stipulated corresponding standards, which also provides effective guarantee for the development of marine drilling operation, and makes the marine drilling environment and conditions obviously improved. 


\section{Design of Automatic Discharge Drive for Drill Pipe of Marine Drilling Rig}

\subsection{Structural Design of Automatic Discharge Drive Device for Drill Pipe of Marine Drilling Rig}

The actual situation of drilling derrick should be considered synthetically in the structure design of drill pipe automatic discharge. This is because the Derrick structure is fixed, in the design process, only can change the shape of the drill pipe of the marine drilling rig to improve the design effect. For example, the drill pipe of XY type marine drilling rig can be used as the driving structure to realize the automatic movement of the drill pipe of the marine drilling rig to the well head during the operation of the drill pipe. Mechanical arm device, can achieve the setting of the grab position of the drill pipe of the marine drilling rig, when the drill pipe of the marine drilling rig moves to the corresponding position area, the mechanical arm will cooperate with the power device to grab the marine drill pipe, and then cooperate with the operation of the track, so that the drill pipe can move along the finger beam to the drilling wellhead.

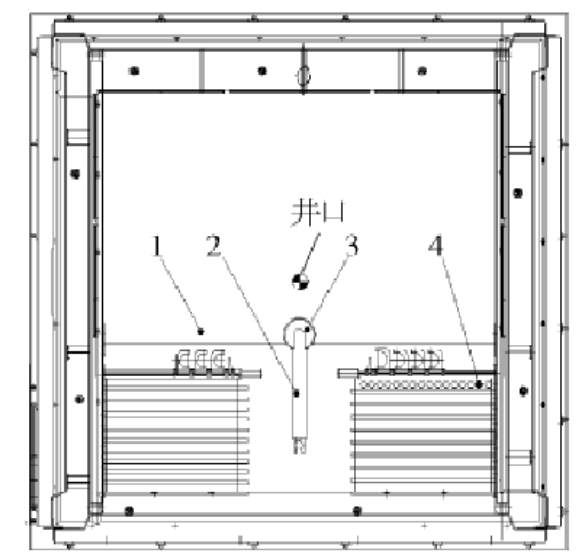

Figure 2 Structure of drill pipe drive for marine drilling rig

\subsection{Power Design of Automatic Discharge Drive Device for Drill Pipe of Marine Drilling Rig}

The drill pipe of marine drilling rig is discharged automatically, and the longitudinal drive and rotary drive can generally be used in the design of power plant. longitudinal drive is generally used for parallel marine drill pipe and XY marine drill pipe, and rotary drive is generally used for star marine drill pipe. Longitudinal power design and rotary power design, need to use hydraulic mode, through accurate mechanical arm control, can make the automatic discharge of drill pipe of marine drilling rig and finger beam alignment, but also can effectively avoid the impact of motion process of automatic discharge of drill pipe of marine drilling rig, improve the stability of automatic discharge of drill pipe of marine drilling rig.

\subsection{Hydraulic Design of Automatic Discharge Drive Device for Drill Pipe of Marine Drilling Rig}

In the process of automatic discharge of drill pipe of marine drilling rig, the hydraulic device used is multistage hydraulic cylinder. The hydraulic device is fixed on the trolley of the mechanical arm, and the cylinder is swung by the running of the trolley to provide power for the hydraulic device. In order to realize the transformation of different speed, multistage hydraulic cylinder needs to change the oil supply of the car gradually on the basis of keeping the car running stably. The expansion of the trolley is closely related to the oil intake of the hydraulic cylinder. In the hydraulic design of the automatic discharge drive device of the drill pipe of the marine drilling rig, a flow valve which can adjust the oil intake can be designed on the hydraulic cylinder, and the effective hydraulic control can be realized by the flow valve. When designing the hydraulic drive device, we should also take into account the running buffer problem of the trolley, which requires multi-stage control of the whole expansion process of the hydraulic cylinder, such as multi-stage speed control, on the structure of the multi-stage hydraulic cylinder, plus multi-stage auxiliary measures. After the 
trolley reaches the specified position, the cylinder can rotate and swing, and this process of rotating and swinging can be achieved by installing a magnet device. The magnet device acts with the flow valve to control the opening and closing of the flow valve, so that the oil intake of the multistage hydraulic cylinder can be controlled, and finally the power supply control purpose of the hydraulic drive can be realized.

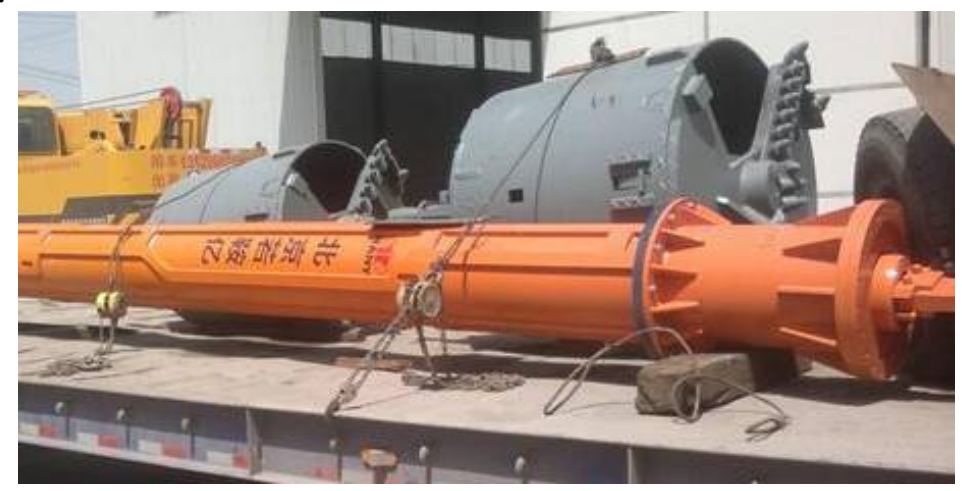

Figure 3 Drilling rigs for marine drilling rigs

\subsection{Electrical Design of Automatic Discharge Drive Device for Drill Pipe of Marine Drilling Rig}

In the process of automatic discharge of drill pipe of marine drilling rig, the movement of driving device can not be separated from the control of electrical system. Electrical components can be used in the design to form the electrical system of the driving device. The inductive components in the electric system of the drive device can form the electronic induction pulse of the car movement by sensing the operation of the car. After receiving the pulse signal, the electric system of the driving device will judge and execute the control instruction of the trolley according to the pulse condition, and then control the stop and operation of the trolley. In order to control the movement of the mechanical arm effectively when the drill pipe of the marine drilling rig is discharged automatically, it is necessary to control the mechanical arm on each track independently. During the drilling process, the pulse signal is inseparable from the magnet order in the system. The control end of the manipulator can design the corresponding motion between the number of pulses and the manipulator in advance. When the electrical system senses that the number of pulses meets the preset, the trolley is stopped and the cylinder can be rotated, thus driving the manipulator to perform the movement of grasping the drill pipe of the marine drilling rig and arranging automatically.

\section{Conclusion}

The marine drilling rig drill pipe automatic discharge drive device is an important offshore drilling operation facility. With the development of national marine drilling field, more and more attention has been paid to the design of automatic discharge drive device for drill pipe of marine drilling rig. The designers of the drill pipe automatic discharge drive device of marine drilling rig need to have a comprehensive and clear understanding of the drill pipe application type and the advantages of the drill pipe application of marine drilling rig, and have a deep grasp of the principle of automatic discharge operation of drill pipe in modern marine drilling rig.

\section{References}

[1] Chen, Jing. Design of Drilling Column Automatic Discharge System for Drilling Platform. Petrochemical Technology, vol. 25, no. 10, pp. 128, 2018.

[2] Pang, Tianshu. Design and Experimental Study on Automatic Discharge System of Drilling Pipe for Geological Drilling. China University of Geosciences (Beijing), 2016.

[3] Liu, Jianli. Design of a Test Device for Vertical Root Emission from the Second Floor Platform of Ocean Platform, China University of Petroleum (East China), 2016. 